\title{
Winter Wheat Seedtime Monitoring through Satellite Remote Sensing Data
}

\author{
Xiaoyu Song ${ }^{1, *}$, Wenjiang Huang ${ }^{1}$, Bei Cui, and Jihong Zhou ${ }^{2}$ \\ ${ }^{1}$ Beijing Agriculture Information Technology Research Center, Beijing, 100097, P.R. China \\ Songxy@nercita.org.cn \\ ${ }^{2}$ Beijing Agro-Technical Extension Station, Beijing, P.R. China
}

\begin{abstract}
Winter wheat seedtime is important for wheat growth. It affects the wheat yield and quality. The objective of this study is monitoring the winter wheat seedtime through remote sensing imagery. Two HJ-1B images and one Landsat5 TM image were used in this study. Three Vegetation Indices, DVI, SAVI and RDVI were calculated. The correlation about the wheat seedtime and VIs were analyzed. The result indicated that wheat growth was negatively correlated with seedtime. Wheat VIs during 40-60 days after sowing is best for seedtime monitoring. The correlation coefficient for DVI of November 22th HJ-1B and seedtime reached -0.51 . The seedtime for whole wheat plant field of Beijing area was inverted through the model. The results show that area for seeded before Sept 30th was about 12.7 thousands ha, 31.8 thousands ha between Oct 1 th and Oct 8 th, and 16.2 thousands ha seeded after Oct 8th during 2009-2010 year.
\end{abstract}

Keywords: Winter wheat, Seedtime, Remote sensing, Landsat5 TM, HJ-1B.

\section{Introduction}

Recent years, warm winter appears in Beijing area frequently since the Global climate warming. High temperature in winter will affects the growth of overwinter crop. Seedtime is important for the management of the wheat [1]. Crop sowing date, sowing pattern, and nitrogen fertilization will affect on weed suppression and Yield [2-3]. Sowing prior to October generally provides enough time for wheat to establish canopy and develop sufficient roots to anchor the plant in the soil [4]. Proper late sowing can avoid wheat bloom before winter and help it safe live through winter Gao Q.L [5-6]. Winter wheat in the Beijing area is typically sown from late September through middle October. During 2009-2010, there are almost 61.3 thousands ha wheat fields in Beijing suburb and the seedtime for different fields is varied. So it is necessary for the farmer or manager to master the wheat area of different seedtime.

This study tries to monitor the winter wheat seedtime in Beijing suburb through satellite remote sensing imagery. Firstly, the wheat plant area was extracted using the threshold of NDVI of three satellite remote sensing images acquired before 2010

\footnotetext{
* Corresponding author.
} 
spring. Then four Vegetation Indices (VIs) for 53 winter wheat fields were calculated and the relationship about the wheat seedtime and VI is analyzed. The study result indicated that the winter wheat growth was negatively correlated in wheat seedtime while it was positive correlated in wheat tiller number. The DVI of November 22th HJ-1B CCD2 image was highly related in the seeded time of wheat, and the correlation coefficient reached -0.51 . Then winter wheat seedtime monitoring model was established based on the HJ-1B image DVI and the wheat sowing date. The seedtime for whole wheat plant field of Beijing area was inverted through the model. The results show that in 2009-2010 year, winter wheat area for seeded before Sept 30th was about 12.7 thousands ha, while area for seeded between Oct 1th and Oct 8th was 31.8 thousands ha, and 16.2 thousands ha wheat was seeded after Oct 8th.

\section{Materials and Methods}

\subsection{The Study Area}

This study was carried on Beijing suburb which ranging from $\mathrm{N} 39^{\circ} 26^{\prime}$ to $41^{\circ} 03^{\prime}$ in latitude and from E $115^{\circ} 25^{\prime}$ to $117^{\circ} 30^{\prime}$ in longitude. During 2009-2010 the winter wheat growth season, 53 wheat fields distributed in Beijing suburb,including Shunyi, Tongzhou, Fangshan, Daxing, Changping, and Huairou were selected as the study samples area (Figure 1). One Landsat5 TM image and two Environment and Disaster Monitoring and Forecasting of small satellite Constellations 1B (HJ-1B satellite) CCD2 images were used in this study.

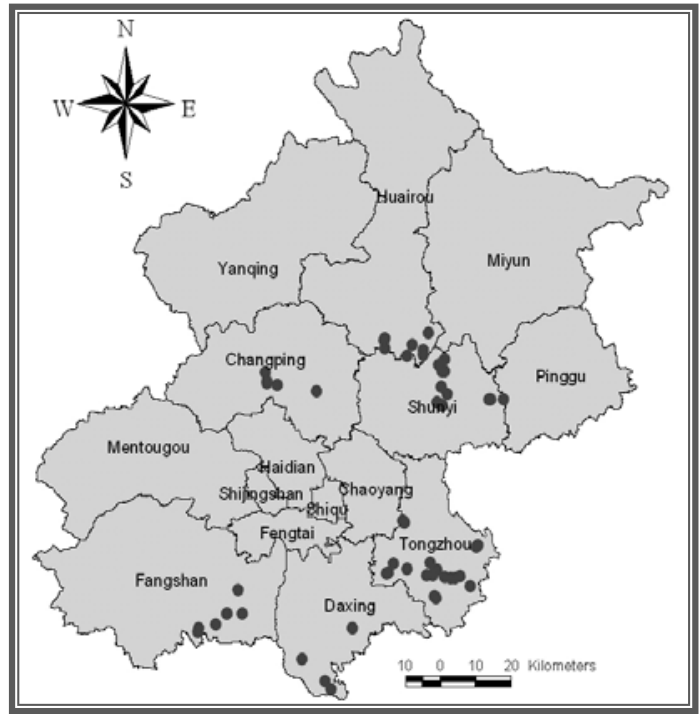

Study wheat fields

Fig. 1. The location of the study area and the distribution of the study wheat fields 


\subsection{Data Collection}

Remote sensing data. One Landsat5 TM image acquired on 24 October, 2009, two Environment and disaster monitoring and forecasting of small satellite constellations 1B (HJ-1B satellite) CCD2 images acquired on 22 November, 19 December, 2009 were used in this study. HJ-1B satellite is equipped with a Charge-Coupled Device camera (CCD) and Infrared Camera (IRS).HJ-1B satellite are designed nadir symmetrical placement, split field and parallel observations [7]. HJ-1B satellite is loaded CCD2 cameral of four spectrum push-broom imaging with the ground swath width of $360 \mathrm{~km}$, the ground pixel resolution of 30 meters. The main parameters of CCD2 camera are shown in table 1 [8-9].

Table 1. Characteristics of HJ-1B CCD2

\begin{tabular}{llrrrrr}
\hline Satellite & Sensor & Bands & $\begin{array}{l}\text { Wavelength } \\
\text { range }(\mu \mathrm{m})\end{array}$ & $\begin{array}{l}\text { Spatial } \\
\text { resolution } \\
(\mathrm{m})\end{array}$ & $\begin{array}{l}\text { Swath } \\
\text { width } \\
(\mathrm{km})\end{array}$ & $\begin{array}{l}\text { Sub-cycle } \\
(\text { days })\end{array}$ \\
\hline HJ-1B & CCD2 & 1 & $0.43-0.52$ & 30 & 360 & 4 \\
& & 2 & $0.52-0.60$ & 30 & 360 & 4 \\
& & 3 & $0.63-0.69$ & 30 & 360 & 4 \\
& & 4 & $0.76-0.90$ & 30 & 360 & 4 \\
\hline
\end{tabular}

Ground survey data. Meanwhile, three ground survey experiments were carried out when the two satellites flied over Beijing area from September to December. The winter wheat sowing date, plant area and seedling emergence numbers data are collected by investigators in all 53 fields. Meanwhile the crop growth information such as wheat winter main stalk number, tiller number and the plant height for each field were also calculated. In order to get the exact data, three $1 \mathrm{~m} 2$ study plots for each filed where located in the middle of field were selected to calculate. Then the location of study plots was recorded by GPS. From the investigation, the sowing period for winter wheat of Beijing area lasts from 23 Sept to 15 Oct in 2009. Three classes of sowing calendar dates recognition namely: early, normal, late in this study. The date range for early is defined the seedtime before $30 \mathrm{Sept}$, normal is 1 Oct to 8 Oct and the late is after 9 Oct.

\subsection{Methods}

The overall methods used in this study are shown as flow chart in Figure.2. Conventional statistics were computed with Excel 2003. The remote sensing data processed and displayed with ENVI 4.1 (ITT 2003). 


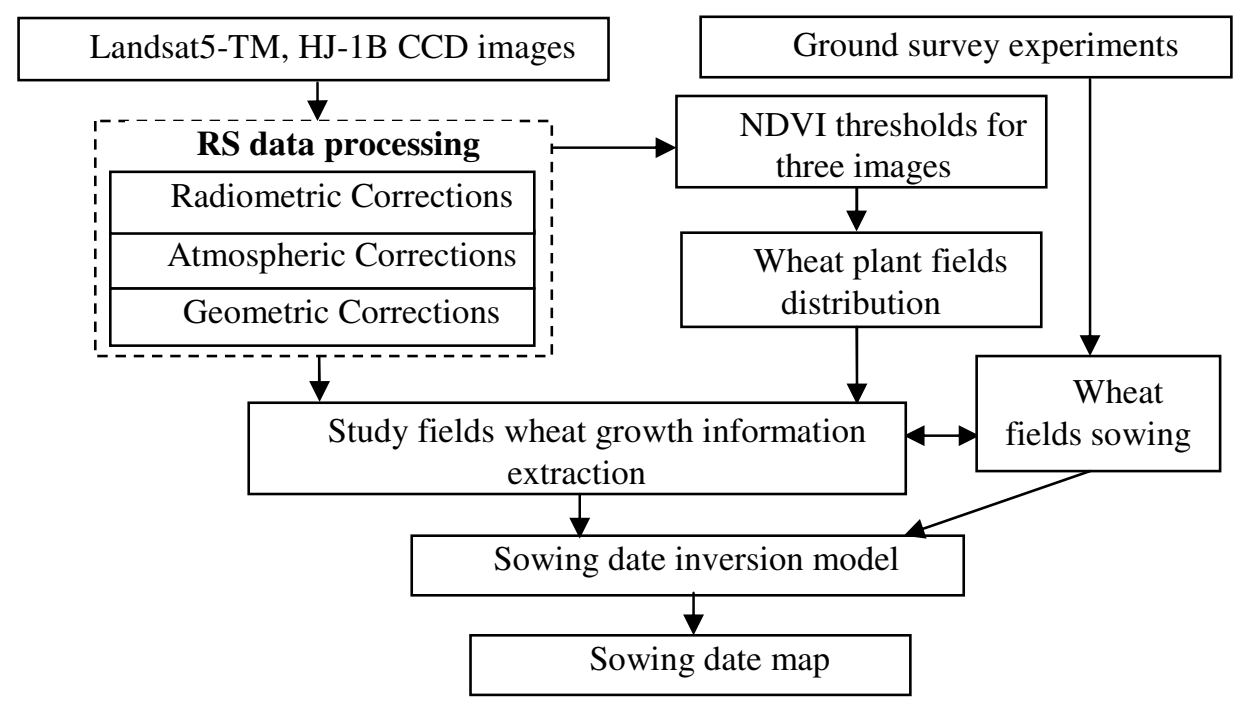

Fig. 2. The flow chart of the study methods

The sequence involves:

(1) TM and HJ-1 data processing, which includes radiometric, atmospheric and geometric corrections;

(2) Using three images NDVI thresholds to extract the winter planted area of 2009-2010 in Beijing suburb.

(3) Four Vegetation Indices (VIs) for 53 winter wheat fields were calculated and the correlation about the wheat seedtime, tiller number and VI were analyzed, then winter wheat seedtime monitoring model was established.

(4) The seedtime for whole wheat plant field of Beijing area was inverted through the model.

\section{Analysis and Conclusion}

\subsection{RS Data Processing}

HJ-1B data was firstly processed by radiometric by convert the DN value of the raw image to the at-satellite radiance image using absolute calibration coefficients (table 2) [10].

$$
L=D N / a+L_{0}
$$


where $L$ represents at-satellite radiance, $D N$ represents the $D N$ value of the raw image, $a$ represents the absolute calibration coefficient of gain, and $L_{0}$ represents the offset. The unit of radiance converted is $W \cdot m^{-2} \cdot s r^{-1} \cdot \mu m^{-1}$.Then the $6 \mathrm{~S}$ (Second Simulation of the Satellite Signal in the Solar Spectrum) model was used for image atmospheric correction (Vermote E., et.al, 1997). The band parameters for HJ-1B CCD2 are adopted that of 1 to 4 band of Landsat-TM5 image in this study. After that, HJ-1B data was processed by geometry correction. The calibrated TM image in this study area was used as the base map, and the same point was selected in TM image and HJ-1B image for correction. Then the typical features such as road intersections adopted by the actual GPS handset were used as verification. Finally, the error of geometric correction was controlled within 1 pixel.

Table 2. The absolute radiometric calibration coefficient of HJ-1B CCD2

\begin{tabular}{|c|c|c|}
\hline HJ-1B CCD2 bands & $\mathrm{A}(\mathrm{DN} / \mathrm{W} \cdot \mathrm{m}-2 . \mathrm{sr}-1 . \mu \mathrm{m}-1)$ & $\mathrm{L}_{0}(\mathrm{~W} . \mathrm{m}-2 . \mathrm{sr}-1 . \mu \mathrm{m}-1)$ \\
\hline Band1 & 0.5759 & 3.4608 \\
\hline Band2 & 0.5488 & 5.8769 \\
\hline Band3 & 0.7537 & 8.0069 \\
\hline Band4 & 0.7753 & 8.8583 \\
\hline
\end{tabular}

\subsection{Winter Wheat Fields Extraction}

The main plants in Beijing suburb are evergreen shrub and winter wheat in field from November to December. During the winter, the plant can easily differentiate from the water body, city land and bare land for the plant NDVI threshold great than that of others features. Firstly, we use the NDVI to extract plant form other land types. In this paper, the threshold great than 0.05 in 24 , Oct, 0.2 in 22, Nov, and 0.1 in 19, Dec is considered as the plant, which can easily differentiate the water body, city land and bare land. Then the winter wheat and the shrub were distinguished by the NDVI curve with the decision trees of ENVI. The evergreen shrub and the winter wheat have the different NDVI curve characters. The shrub NDVI curve shows obvious decrease from Oct to Dec while the winter wheat increases from Oct to Nov but decrease from Nov to Dec. Based on the difference of the NDVI curves, the winter wheat fields was extracted (figure 4). 


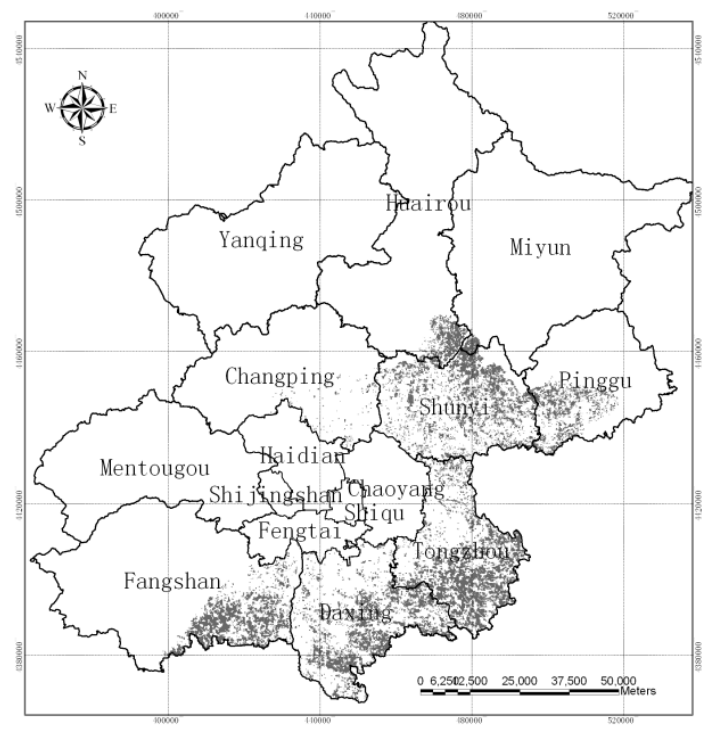

Wheat fields

No-Wheat fields

Fig. 3. The winter wheat extraction map

\subsection{Statistical Correlation}

Spectral characteristics of crop fields are changed after sowing. Values of near infrared reflectance (band 2) increase during 40-60 days after sowing. Four vegetation indices (VI), NDVI, DVI, SAVI and RDVI are calculated from TM and HJ-1 image [11-14]. The definition for those four vegetation indices is listed in table 3 .

Table 3. The vegetation index definition for Landsat5 TM and HJ-1B CCD2 image

\begin{tabular}{cclc}
\hline Vegetation Index & Bands & \multicolumn{1}{c}{ Definition } & \multicolumn{1}{c}{ Author } \\
\hline NDVI & B3,B4 & $N D V I=\left(R_{4}-R_{3}\right) /\left(R_{4}+R_{3}\right)$ & Rouse, et al., (1974) \\
DVI & B3,B4 & $D V I=\left(R_{4}-R_{3}\right)$ & Jordan, et al., (1969) \\
SAVI & B3,B4 & SAVI $=(1+0.5) *\left(R_{4}-R_{3}\right) /\left(R_{\iota}\right.$ & Huete, et al., (1988) \\
RDVI & B3,B4 & $\left.R D V I=\left(R_{4}-R_{3}\right) / \sqrt{\left(R_{4}+R_{3}\right.}\right)$ & Rougean \& Breon, (1995) \\
\hline
\end{tabular}

Then, analysis about the VI and the winter wheat growth investigation data are carried on. The sowing date has negative relationship with the winter wheat ground survey LAI. The correlation coefficient between sowing date and Oct LAI reached -0.23 , increase to -0.54 in Dec then decrease to -0.12 in Nov. Meanwhile, the relationship between wheat VI and sowing date also analyzed (Table 4). 
Table 4. The correlation coefficient between sowing date

\begin{tabular}{llllll}
\hline Vegetation Index & sowing date & Vegetation Index & $\begin{array}{c}\text { Sowing } \\
\text { date }\end{array}$ & Vegetation Index & sowing date \\
\hline $10 / 24$ & -0.136 & $11 / 22$ HJ-NDVI & $-0.458^{* *}$ & $12 / 19$ HJ-NDVI & -0.142 \\
TM-NDVI & & $11 / 22$ HJ-DVI & $-0.510^{* *}$ & $12 / 19$ HJ-DVI & -0.182 \\
$10 / 24$ TM-DVI & -0.111 & $11 / 22$ HJ-RDVI & $-0.487^{* *}$ & $12 / 19$ HJ-RDVI & -0.167 \\
$10 / 24$ TM-RDVI & -0.124 & $11 / 22$ HJ-SAVI & $-0.458^{* *}$ & $12 / 19$ HJ-SAVI & -0.142 \\
\hline $10 / 24$ TM-SAVI & -0.136 & $11 / 22$ &
\end{tabular}

** : $\mathrm{r}(0.01, \quad 53)=0.343$

The table 4 indicated that wheat spectral characteristics during 40-60 days after sowing is best for seedtime monitored.the DVI of November 22th HJ-1B CCD2 image was highly related in the seeded time of wheat, and the correlation coefficient reached -0.510. Then winter wheat seedtime monitoring model was established based on the HJ-1B image DVI and the ground data (Figure 4). Three classes of sowing calendar dates recognition namely: early, normal, late in this study. The date range for early is before 30 Sept, for normal is 1 Oct to 8 Oct and the late is after 8 Oct.

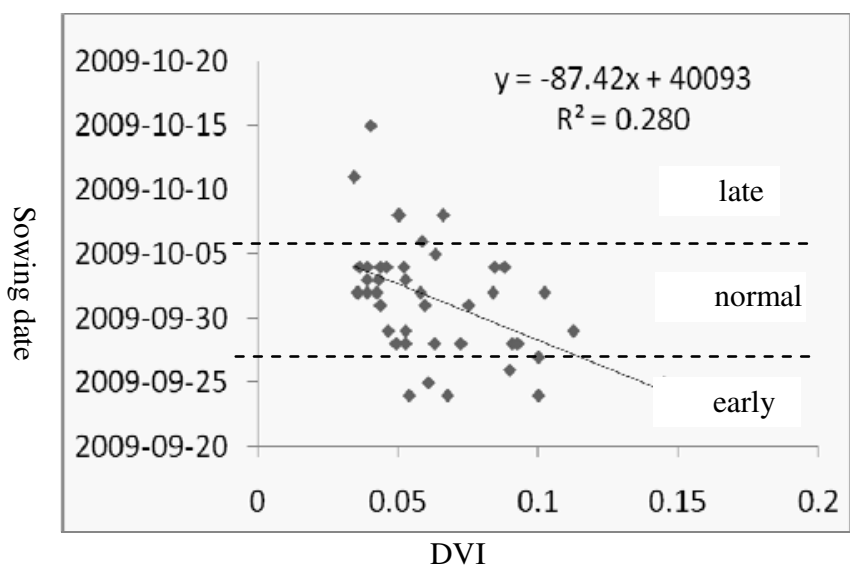

Fig. 4. The scatter-plot of sowing date and HJ-1 CCD2 DVI

\subsection{Results}

Figure 5 shows the result of winter wheat sowing date supervising through remote sensing data. The seedtime for whole wheat plant field of Beijing area was inverted through the model. The results show that in 2009-2010 year, winter wheat area for seeded before Sept 30th was about 12.7 thousands ha, while area for seeded between 
Oct 1 th and Oct 8 th was 31.8 thousands ha, and 16.2 thousands ha wheat was seeded after Oct 8th. Then the wheat planting area of different seedtime for five main crop counties, Daxing, Tongzhou, Shunyi, Fangshan and Changping was calculated through the seedtime map and the statistic results are list in table 5.

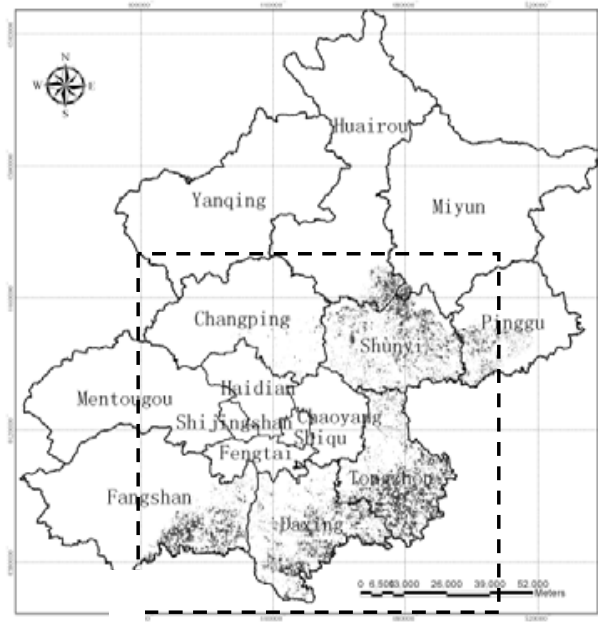

Sowing date early

a: Seedtime map for whole Beijing area

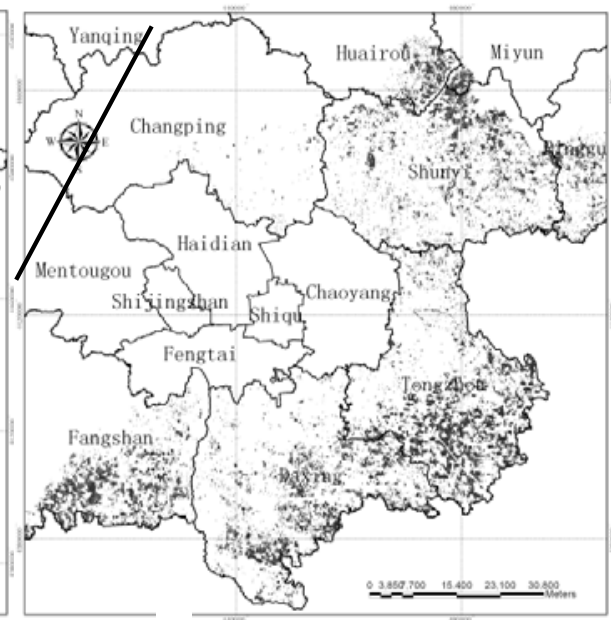

No-Wheat fields

b: Seedtime map for main wheat planted counties of Beijing

Fig. 5. 2009-2010 Winter wheat Seedtime map of Beijing suburb

Table 5. Statistic results of wheat planting area of different sowing date for the main crop counties of Beijing suburb in 2009

\begin{tabular}{llll}
\hline Country name & Early sowing(ha) & Normal sowing & Late sowing \\
\hline Daxing & 2800.00 & 9666.67 & 1933.33 \\
Tongzhou & 3388.33 & 10727.20 & 1684.47 \\
Shunyi & 5066.67 & 8266.67 & 770.00 \\
Fangshan & 2010.67 & 9529.00 & 460.33 \\
Changping & 453.33 & 209.35 & 8.00 \\
\hline
\end{tabular}

\subsection{Conclusion and Discussion}

In this paper, the winter wheat seedtime monitoring model was established based on the HJ-1B image DVI and the ground data. The seedtime for whole wheat plant field of Beijing area was inverted through the model. The result shows a good agreement with the statistic data from Beijing agriculture technique popularizing station. It indicated 
that the winter wheat growth was negatively correlated with wheat seedtime in winter and the wheat spectral characteristics during 40-60 days after sowing is best for seedtime monitoring. The results of this study suggest that seedtime monitoring using RS data was reliable and feasible.

The study is only one year's result, although the warm winter appears in Beijing area frequently in recent years, the winter of 2009-2010 is a typical cold winter. The average temperature from $2009 \mathrm{Dec}$ to $2010 \mathrm{Feb}$ is negative $3.5^{\circ} \mathrm{C}$, it is lower than the recent 10 year's average temperature by $1.6^{\circ} \mathrm{C}$. So it affects the growth of the winter wheat in different seedtime. More study about the different seedtime wheat growth characters in warm winter should be carried on in the future.

Acknowledgment. This work was supported by Beijing Natural Science Foundation (Grant No. 4092017) and Youth Scientific Research foundation of BAAFS.

\section{References}

1. Liu, L., Zhao, C.J., Wang, J.H., Song, X.Y., Huang, W.J., Li, C.J.: Satellite Remote Sensing of Winter Wheat Seedtime and its Application. Remote Sensing Information (in Chinese with English abstract) 1, 28-31 (2005)

2. Lars, K., Jannie, O., Jacob, W.: Crop Density, Sowing pattern, and Nitrogen Fertilization. Effects on Weed Suppression and Yield in Spring Wheat. Weed Science 56, 97-102 (2008)

3. Keyvan, S.: The effect of sowing date and row spacing on yield and yield components on Hashem chickpea variety under rainfed condition. African Journal of Biotechnology 9(1), 007-0014 (2010), http: / / www. academicjournals . org / AJB

4. Edwards, J.: Factors affecting wheat Germination and stand establishment in hot soils. Oklahoma Cooperative Extension Service. Division of Agricultural Sciences and Natural Resources, Pss-2256, August 18 (2008),

http: //pods.dasnr.okstate.edu/docushare/dsweb/Get/

Document-5319/PSS-2256.pdf

5. Gao, Q.L., Xue, X., Liang, Y.J., Wu, Y.E., Ru, Z.G.: Studies on regulating sowing time of wheat under the warm winter conditions. Journal of Triticeae Crops (in Chinese with English abstract) 22(2), 46-50 (2002)

6. William, S., Donald, W., Harry, S., Steve, S., Robert, P.: Tillage Method and Sowing Rate Relations for Dryland Spring Wheat, Barley and Oat. Pacific Northwest Conservation Tillage Handbook Series No.30, Chapter 2- Conservation Tillage Systems and Equipment (2005)

7. Yi, L., Wang, X., Liu, B.: Researches on HJ-1 satellite image quality and land use classification precision. Remote Sensing for Land \& Resources (in Chinese with English abstract) 81, 74-77 (2009)

8. Jia, F.J., Wu, Y.L., Huang, Y., Cao, D.J.: Design and On-orbit application of CCD Camera on HJ-1A/B Satellites. Spacecraft Engineering (in Chinese with English abstract) 18(6), 37-42 (2009)

9. Ren, P., Yang, C.J., Zhou, J.M.: The Evaluation and Application Study on CCD Multi-spectral Remote Data Characteristics of HJ-1A/B Satellites. Remote Sensing Technology and Application 25(1), 138-142 (2010) 
10. Zhu, J., Wu, Y.L., Shen, Z., Li, T.: Analysis of System-level Radiometric Calibration Data for HJ-1A/B Wide Coverage CCD Camera. Spacecraft Engineering (in Chinese with English abstract) 18(5), 73-79 (2009)

11. Rouse, J.W., Hass, R.H., Schell, J.A., Deering, D.W.: Monitoring the vernal advancement of retrogradation of natural vegetation. NASA/GSFC, Type III, Final Report. Greenbelt, MD. 1974, 371 (1974)

12. Jordan, C.F.: Derivation of Leaf Area Index from Quality of Light on the Forest Floor. Ecology 50, 663-666 (1969)

13. Huete, A.R.: A Soil-Adjusted Vegetation Index (SAVI). Remote Sensing of Environment 25, 295-309 (1988)

14. Rougean, J.-L., Breon, F.M.: Estimating PAR absorbed by vegetation from bidirectional reflectance measurements. Remote Sens. Environ. 51, 375-384 (1995) 